\title{
Ex vivo Comparison of Intraocular Pressure Fluctuation during Pars Plana Vitrectomy Performed Using 25- and 27-Gauge Systems
}

\author{
Yoichiro Shinkai Kazuhito Yoneda Chie Sotozono \\ Department of Ophthalmology, Kyoto Prefectural University of Medicine, Kyoto, Japan
}

\section{Keywords}

Retina · Vitrectomy · Intraocular pressure - Intraocular pressure fluctuation · Fluid-gas control

\begin{abstract}
Introduction: The purpose of this study was to compare intraoperative intraocular pressure fluctuation using different aspiration systems and 25- and 27-gauge vitreous surgery probes. Methods: Ex vivo, pars plana, 25- and 27-gauge vitreous surgery was performed on 4 porcine eyes, and IOP fluctuations were evaluated. We performed 3-port vitrectomy using the Constellation ${ }^{\circledR}$ Vision or the EVA ${ }^{\circledR}$ Phaco-Vitrectomy system. Each 20-s experiment was conducted 5 times for each set of conditions, each with the same substituted balanced salt solution. Real-time intraoperative intraocular pressure measurement was performed at the distal end of the infusion tube. Intraocular pressure was measured during core vitrectomy, core vitrectomy with fluid aspiration, peripheral vitreous shaving with scleral indentation, and fluidgas exchange. The Mann-Whitney $U$ test was used to evaluate statistical significance. Results: Mean \pm standard deviation intraoperative intraocular pressure fluctuation during 25- and 27-gauge core vitrectomy was $15.9 \pm 1.6$ and $11.9 \pm$ $1.4 \mathrm{~mm} \mathrm{Hg}$, respectively ( $p<0.05)$, using the Constellation system; $23.2 \pm 1.4$ and $14.1 \pm 0.7 \mathrm{~mm} \mathrm{Hg}$, respectively $(p<$
\end{abstract}

karger@karger.com

(c) 2020 S. Karger AG, Basel

www.karger.com/ore

Karger"
$0.001)$, using the EVA vacuum mode; and $15.0 \pm 0.5$ and $11.5 \pm 1.4 \mathrm{~mm} \mathrm{Hg}$, respectively $(p<0.05)$, using the EVA flow mode. The smallest intraoperative intraocular pressure fluctuations during core vitrectomy with fluid aspiration, peripheral vitreous shaving with scleral indentation, and fluid-gas exchange were all achieved using the 27-gauge EVA flow mode; these values were $14.2 \pm 0.4,35.7 \pm 0.9$, and $6.4 \pm 0.2$ $\mathrm{mm} \mathrm{Hg}$, respectively. Conclusion: Regardless of the aspiration system, intraoperative intraocular pressure fluctuation was lower during 27-gauge than during 25-gauge vitrectomy. The 27-gauge EVA flow mode produced optimal intraoperative intraocular pressure stability.

C) 2020 S. Karger AG, Basel

\section{Introduction}

With the development of vitreous surgery, 27-gauge $(27 \mathrm{G})$ probes are increasingly being used because they are less invasive and result in better prognoses; however, intraocular pressure (IOP) fluctuations during pars plana vitrectomy (PPV) can cause expulsive choroidal hemorrhage, retinal ischemia, vitreous hemorrhage, choroidal detachment, and optic nerve ischemia [1-6]. In patients with proliferative diabetic retinopathy and retinal vein occlusion, the effects of IOP fluctuations are particularly 
Table 1. The settings of vitreous machines

\begin{tabular}{llllll}
\hline Machines & \multicolumn{3}{l}{ Settings } & & \\
\cline { 2 - 6 } & $\begin{array}{l}\text { IOP control, AIC, } \\
\mathrm{mm} \mathrm{Hg}\end{array}$ & $\begin{array}{l}\text { cut rate, } \\
\mathrm{cpm}\end{array}$ & $\begin{array}{l}\text { aspiration } \\
\text { pressure, } \\
\mathrm{mm} \mathrm{Hg}\end{array}$ & $\begin{array}{l}\text { flow, } \\
\mathrm{cc} / \mathrm{min}\end{array}$ \\
\hline Constellation 25G & 30 & & 7,500 & 650 & \\
Constellation 27G & 30 & & 7,500 & 650 & \\
EVA (25G vacuum mode) & & $20-40$ & 8,000 & 400 & \\
EVA (27G vacuum mode) & & $20-40$ & 8,000 & 600 & 15 \\
EVA (25G flow mode) & & $20-40$ & 8,000 & & 15 \\
EVA (25G flow mode) & & $20-40$ & 8,000 & & \\
\hline
\end{tabular}

IOP, intraocular pressure; AIC, automatic infusion compensation.

pronounced, especially in eyes with impaired retinal and optic nerve blood flow [6, 7]. In short, detecting IOP fluctuation during PPV may improve the safety of the procedure.

Michelson et al. [8] were the first to demonstrate, in healthy volunteers, that a rapid rise in IOP leads to decreased blood flow in the retina and optic disc. Ex vivo experiments have also been performed in animal models $[7,9-12]$, one of which suggested that a rapid increase in IOP during PPV may lead to retinal ganglion cell damage [9]. To date, IOP fluctuations of up to $110 \mathrm{~mm} \mathrm{Hg}$ have been demonstrated during vitrectomy in an animal model [10], whereas in vitrectomy of the human eye, IOP has proven to fluctuate in the range of $0-120 \mathrm{~mm} \mathrm{Hg}[6,11]$. These results were obtained using the Accurus ${ }^{\circledR}$ Surgery System (Alcon Laboratories, Inc., Fort Worth, TX, USA), which is dependent on vented gas forced infusion. Yang et al. [13] compared the Accurus Surgery system to the Constellation ${ }^{\circledR}$ Vision system (Alcon Laboratories, Inc.) by directly monitoring IOP in vivo. IOP fluctuations were larger during vitrectomy using the Accurus than the Constellation.

In a 2010 pilot study, Oshima et al. [14] demonstrated the initial feasibility and safety of a novel $27 \mathrm{G}$ microincision vitrectomy surgery system. Since then, the use of $27 \mathrm{G}$ sutureless vitrectomy surgery has been on the increase, mostly for the treatment of macular disease [15-18]. In 2019 , we reported the results of a retrospective multicenter study where we concluded that $27 \mathrm{G} \mathrm{PPV} \mathrm{is} \mathrm{a} \mathrm{safe}$ and effective treatment for primary retinal detachment [19]. Currently, more than half of the surgeons in Japan use $25 \mathrm{G}$ and $27 \mathrm{G}$ systems because they are minimally invasive. The most commonly used systems for microincision vitrectomy surgery are the Constellation and the EVA Phaco-Vitrectomy (D.O.R.C. Dutch Ophthalmic Research Center [International] B.V., Zuidland, The
Netherlands) systems. Both are equipped with distinctive pressure control systems that can maintain IOP at a fixed value: in the case of the Constellation system, it is the IOP control (IOPc) feature, and in the case of the EVA system, it is the automatic infusion compensation (AIC) feature. In our previous study, mentioned above, all surgeons performed $27 \mathrm{G}$ vitrectomy with either the Constellation or the EVA system [19].

A limited number of studies have revealed, using $23 \mathrm{G}$ and $25 \mathrm{G}$ probes, that the IOPc feature of the Constellation system more effectively reduced IOP fluctuation than did the vented gas forced infusion system [20,21]. To the best of our knowledge, IOP fluctuation during $27 \mathrm{G}$ PPV performed with various vitrectomy systems has not been investigated. The objective of the present study was to compare IOP fluctuation during vitrectomy with a $25 \mathrm{G}$ probe with that during vitrectomy with a $27 \mathrm{G}$ probe, on 2 different vitrectomy instruments.

\section{Materials and Methods}

In this study, we used 4 fresh porcine eyes, which were kept at $4^{\circ} \mathrm{C}$, from a slaughterhouse within 1 day after death. The setup of vitreous surgery was prepared according to general clinical standards. For the first eye, $25 \mathrm{G}$ vitrectomy was conducted using the Constellation system, with the IOPc pressure set to $30 \mathrm{~mm} \mathrm{Hg}$, cutting rate set to 7,500 cuts per minute $(\mathrm{cpm})$, and aspiration pressure set to $650 \mathrm{~mm} \mathrm{Hg}$. For the second eye, 27G vitrectomy was performed under the same conditions. For the third eye, $25 \mathrm{G}$ vitrectomy was conducted using the EVA system, with the AIC pressure set to $20-40 \mathrm{~mm} \mathrm{Hg}$, cutting rate set to $8,000 \mathrm{cpm}$, aspiration pressure set to $400 \mathrm{~mm} \mathrm{Hg}$ using the vacuum mode, and flow rate set to $15 \mathrm{~mL} / \mathrm{min}$ using the flow mode. For the fourth eye, $27 \mathrm{G}$ vitrectomy was conducted using the EVA system under the same conditions, apart from the aspiration pressure, which was set to $600 \mathrm{~mm} \mathrm{Hg}$. A summary of the settings is displayed in Table 1.

In each case, we performed standard 3-port vitrectomy. Trocars $(25 \mathrm{G}$ or $27 \mathrm{G})$ were inserted perpendicularly into the pars pla- 


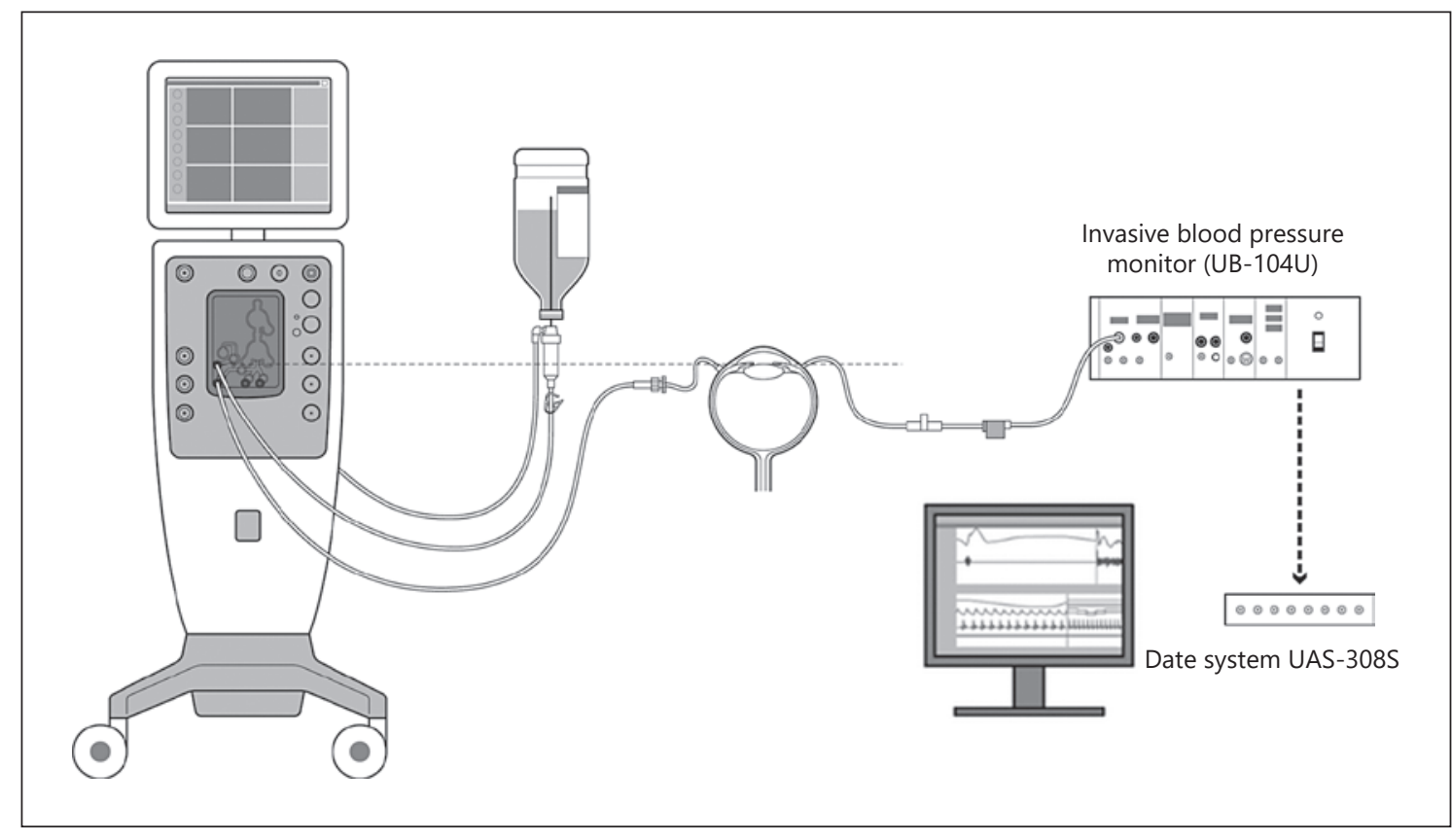

Fig. 1. Schematic of the experimental setup to measure IOP fluctuation during PPV with the EVA ${ }^{\circledR}$ Phaco-Vitrectomy system. The invasive blood pressure monitor and the liquid level in the bottle of BSS are positioned at the same level as the porcine eye. IOP, intraocular pressure; PPV, pars plana vitrectomy; BSS, balanced salt solution.

na. We performed core vitrectomy for all 4 eyes, extensively removing vitreous gel around the irrigation cannula with the $25 \mathrm{G}$ or $27 \mathrm{G}$ cutter, as vitreous gel impairs IOP measurement. Thereafter, the infusion tube was inserted into the vitreous cavity $3.5 \mathrm{~mm}$ posterior to the limbus. After confirming that the balanced salt solution (BSS) flowed freely through the cannula, we performed realtime measurement of IOP at the distal end of the infusion tube, using an invasive blood pressure monitor (LifeSource ${ }^{\circledR}$ UB-104U; Auto Control Medical Inc., Mississauga, ON, Canada). The infusion tube and pressure monitor were positioned at the same level as the eye during evaluation. The data were immediately sent to the UAS-308S data collection system (Unique Medical Co., Ltd., Tokyo, Japan). The experimental setup is portrayed in Figure 1.

We measured real-time IOP for all 4 sets of conditions, conducting each 20-s experiment 5 times. Each experiment was initiated only after pressure fluctuation due to injection of the BSS had subsided. We continuously monitored the IOP to detect fluctuations, at an acquisition rate of $250 \mathrm{samples} / \mathrm{min}$, and calculated mean values. First, IOP was monitored during core vitrectomy, where the foot pedal was fully pressed down (vitreous cutter on) 5 $s$ after the start of IOP measurement and released (vitreous cutter off) $15 \mathrm{~s}$ after the start of measurement. Second, IOP was monitored during core vitrectomy with fluid aspiration, with the same intervals as above. Third, IOP was monitored during peripheral vitreous shaving with scleral indentation, where the foot pedal was pressed down fully for the entire $20 \mathrm{~s}$ of measurement. In this case, we initiated scleral indentation $5 \mathrm{~s}$ after the start of IOP measurement and terminated it $15 \mathrm{~s}$ after the start of measurement. Fourth, IOP was monitored during fluid-gas exchange, where the foot pedal was pressed down fully and fluid aspiration initiated $5 \mathrm{~s}$ after the start of IOP measurement. The foot pedal was released and fluid aspiration switched to gas aspiration $15 \mathrm{~s}$ after the start of measurement. Real-time IOP data were imported into Microsoft ${ }^{\circledR}$ Excel $^{\circledR}$ 2016 (Microsoft Corp., Redmond, WA, USA), and graphs were plotted. We defined IOP fluctuation as the difference between maximum and minimum IOP values.

\section{Statistical Analysis}

Continuous variables were indicated as the mean \pm the standard deviation. Where appropriate, the Mann-Whitney U test was used to evaluate statistical significance. Statistical analysis was performed using IBM SPSS ${ }^{\circledR}$ Statistics 24.0 (IBM Corp., Armonk, NY, USA). A $p$ value of $<0.05$ was considered statistically significant.

\section{Results}

Figure $2 \mathrm{a}$ is a plot of the mean dynamic change in IOP during core vitrectomy. Mean IOP fluctuation during $25 \mathrm{G}$ and $27 \mathrm{G}$ core vitrectomy was $15.9 \pm 1.6$ and $11.9 \pm$ $1.4 \mathrm{~mm} \mathrm{Hg}$, respectively $(p<0.05)$, using the Constellation system; $23.2 \pm 1.4$ and $14.1 \pm 0.7 \mathrm{~mm} \mathrm{Hg}$, respectively $(p<0.001)$, using the EVA vacuum mode; and $15.0 \pm$ 0.5 and $11.5 \pm 1.4 \mathrm{~mm} \mathrm{Hg}$, respectively $(p<0.05)$, using the EVA flow mode.

Figure $2 \mathrm{~b}$ is a plot of the mean dynamic change in IOP during core vitrectomy with fluid aspiration. Mean IOP 

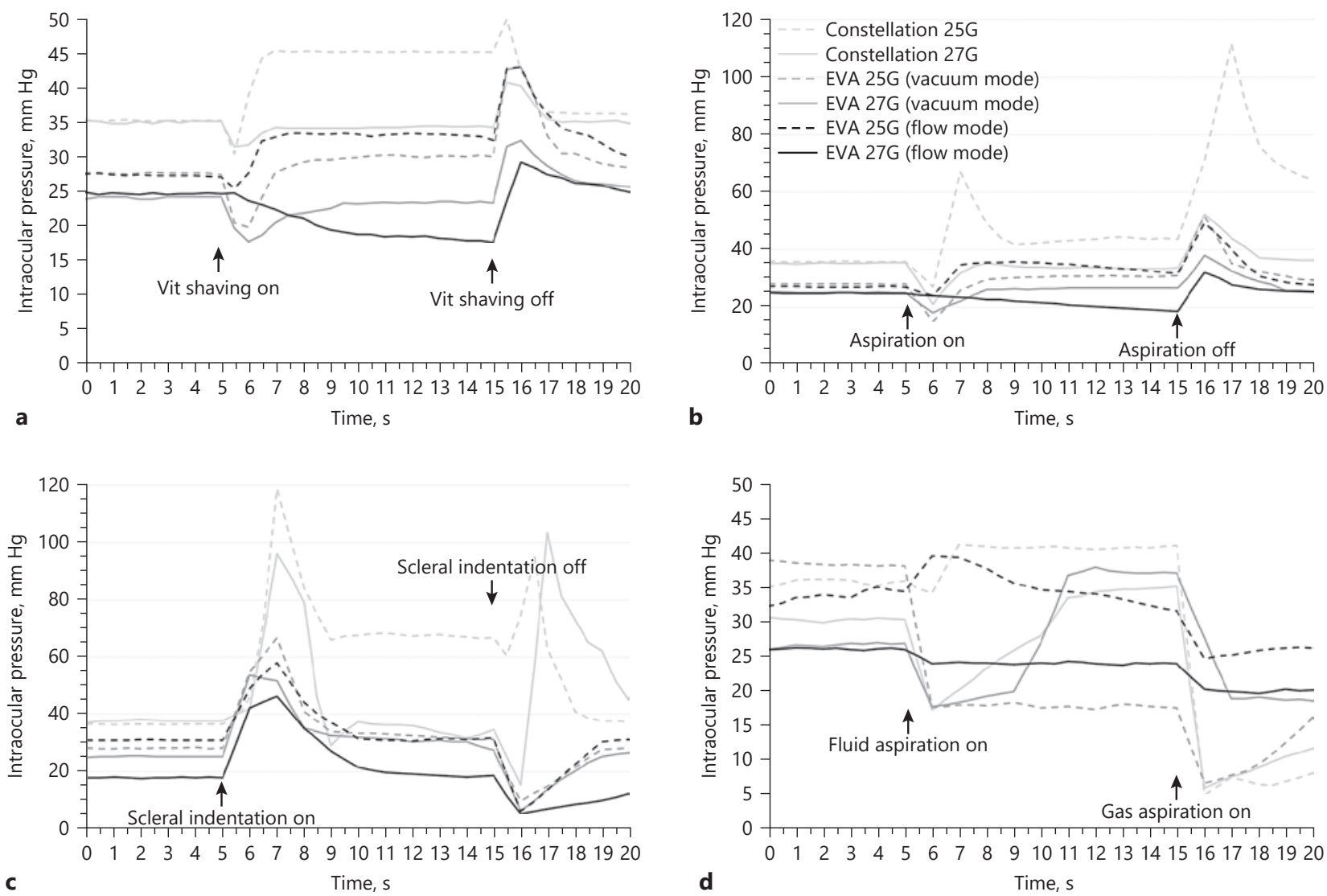

Fig. 2. a IOP fluctuations during core vitrectomy using various instruments and settings. We pressed the foot pedal down completely (vitreous cutter on) $5 \mathrm{~s}$ after the start of measurement and released it (vitreous cutter off) $15 \mathrm{~s}$ after the start of measurement. b IOP fluctuations during core vitrectomy with fluid aspiration using various instruments and settings. We pressed the foot pedal down completely (vitreous cutter on) $5 \mathrm{~s}$ after the start of measurement and released it (vitreous cutter off) $15 \mathrm{~s}$ after the start of measurement. c
IOP fluctuations during peripheral vitreous shaving with scleral indentation. We pressed the foot pedal down completely (vitreous cutter on) for the entire $20 \mathrm{~s}$. We initiated scleral indentation $5 \mathrm{~s}$ after the start of measurement and terminated it $15 \mathrm{~s}$ after the start of measurement. d IOP fluctuations during fluid-gas exchange. We pressed the foot pedal down fully and initiated fluid aspiration $5 \mathrm{~s}$ after the start of measurement. We switched to gas aspiration $15 \mathrm{~s}$ after the start of measurement. IOP, intraocular pressure. fluctuation during $25 \mathrm{G}$ and $27 \mathrm{G}$ vitreous aspiration was $82.0 \pm 2.6$ and $31.5 \pm 1.0 \mathrm{~mm} \mathrm{Hg}$, respectively $(p<0.001)$, using the Constellation system; $35.3 \pm 1.0$ and $19.6 \pm 0.5$ $\mathrm{mm} \mathrm{Hg}$, respectively $(p<0.001)$, using the EVA vacuum mode; and $26.1 \pm 0.6$ and $14.2 \pm 0.4 \mathrm{~mm} \mathrm{Hg}$, respectively $(p<0.001)$, using the EVA flow mode.

Figure $2 \mathrm{c}$ is a plot of the mean dynamic change in IOP during peripheral vitreous shaving with scleral indentation. Mean IOP fluctuation during $25 \mathrm{G}$ and $27 \mathrm{G}$ peripheral vitreous shaving was $92.4 \pm 2.4$ and $82.9 \pm 2.3 \mathrm{~mm}$ $\mathrm{Hg}$, respectively $(p<0.001)$, using the Constellation system; $53.6 \pm 2.0$ and $43.6 \pm 0.8 \mathrm{~mm} \mathrm{Hg}$, respectively $(p<$
0.001 ), using the EVA vacuum mode; and $47.1 \pm 1.0$ and $35.7 \pm 0.9 \mathrm{~mm} \mathrm{Hg}$, respectively $(p<0.001)$, using the EVA flow mode.

Figure $2 \mathrm{~d}$ is a plot of the mean dynamic change in IOP during fluid-gas exchange. Mean IOP fluctuation during $25 \mathrm{G}$ and $27 \mathrm{G}$ fluid-gas exchange was $36.3 \pm 0.7$ and 28.1 $\pm 1.0 \mathrm{~mm} \mathrm{Hg}$, respectively $(p<0.001)$, using the Constellation system; $30.6 \pm 1.1$ and $19.6 \pm 0.8 \mathrm{~mm} \mathrm{Hg}$, respectively ( $p<0.001)$, using the EVA vacuum mode; and 14.6 \pm 0.4 and $6.4 \pm 0.2 \mathrm{~mm} \mathrm{Hg}$, respectively $(p<0.001)$, using the EVA flow mode. All the above results are presented in Table 2. 
Table 2. The results of the IOP fluctuations $(\mathrm{mm} \mathrm{Hg})$ during various settings

\begin{tabular}{llll}
\hline & \multicolumn{2}{l}{ IOP fluctuation } & \multirow{2}{*}{$p$ value } \\
\cline { 2 - 3 } & $25 G$ & $27 G$ & \\
\hline Constellation & & & \\
$\quad$ Core vitrectomy & $15.9 \pm 1.6$ & $11.9 \pm 1.4$ & $<0.05$ \\
$\quad \begin{array}{l}\text { Aspiration mode } \\
\text { Scleral indentation }\end{array}$ & $82.0 \pm 2.6$ & $31.5 \pm 1.0$ & $<0.001$ \\
$\quad$ Fluid-gas exchange & $36.4 \pm 2.4$ & $82.9 \pm 2.3$ & $<0.001$ \\
EVA (vacuum) & & $28.1 \pm 1.0$ & $<0.001$ \\
$\quad$ Core vitrectomy & $23.2 \pm 1.4$ & $14.1 \pm 0.7$ & $<0.001$ \\
$\quad \begin{array}{l}\text { Aspiration mode } \\
\text { Scleral indentation }\end{array}$ & $35.3 \pm 1.0$ & $19.6 \pm 0.5$ & $<0.001$ \\
Fluid-gas exchange & $53.6 \pm 2.0$ & $43.6 \pm 0.8$ & $<0.001$ \\
& $30.6 \pm 1.1$ & $19.3 \pm 0.6$ & $<0.001$ \\
\hline
\end{tabular}

$\mathrm{IOP}$, intraocular pressure.

Figure 3 is a plot of mean IOP fluctuations using $25 \mathrm{G}$ and $27 \mathrm{G}$ vitrectomy for the various vitreous conditions. Mean IOP fluctuation was $39.4 \pm 24.7 \mathrm{~mm} \mathrm{Hg}$ during 25G vitrectomy and $26.3 \pm 20.4 \mathrm{~mm} \mathrm{Hg}$ during $27 \mathrm{G}$ vitrectomy. The range of IOP fluctuation was smaller during $27 \mathrm{G}$ vitrectomy than during $25 \mathrm{G}$ vitrectomy, with a mean difference of $13.0 \pm 22.5 \mathrm{~mm} \mathrm{Hg}(p<0.001)$.

\section{Discussion/Conclusion}

In the present study, we conducted an experiment using the Constellation and EVA systems, the main instruments in use for various types of vitreous surgery in Japan. Other studies have been conducted to describe IOP fluctuations during vitrectomy with $23 \mathrm{G}$ and $25 \mathrm{G}$ probes using the IOPc feature of the Constellation system [20, 21]. However, to the best of our knowledge, IOP fluctuation during $27 \mathrm{G}$ PPV has not been investigated. Furthermore, many Japanese surgeons use 27G probes even for difficult cases such as retinal detachment [19]. Therefore, we conducted experiments using $25 \mathrm{G}$ and $27 \mathrm{G}$ probes.

The Constellation system was the first vitrectomy instrument to incorporate an IOP compensation feature, which they termed "integrated pressure injection with IOP control." It utilizes noninvasive flow sensors to measure injections into the eye and corrects IOP in real time to maintain the desired pressure. The EVA system has the AIC feature, similar to IOPc, which stabilizes IOP by progressively increasing infusion via bottle pressure.

As in a previous report [7], intraoperative IOP fluctuation was the highest during peripheral vitreous shaving

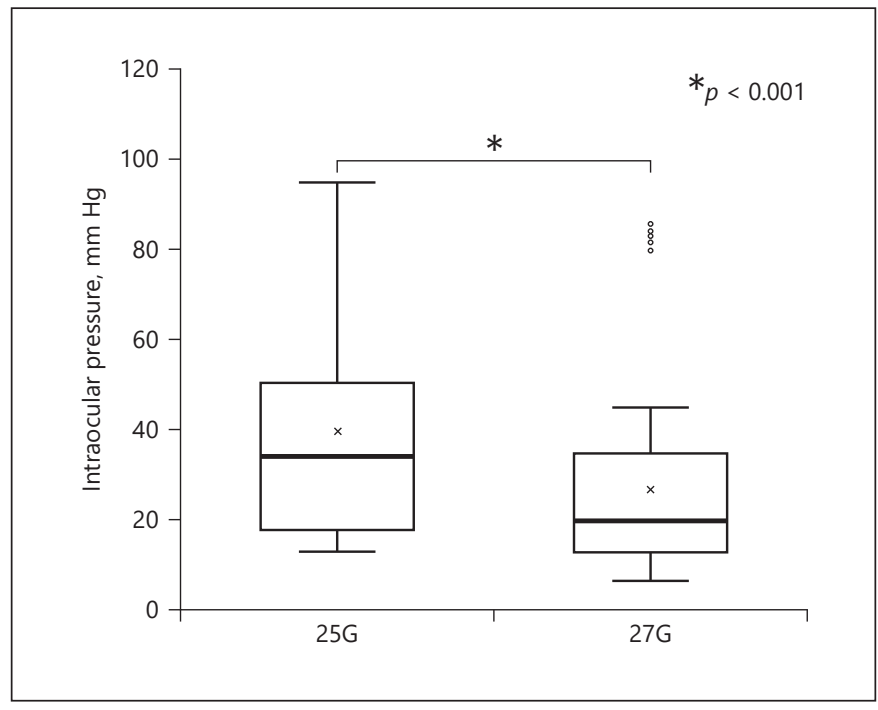

Fig. 3. Box plots of IOP fluctuations with 25- and 27-gauge vitrectomy systems for the various vitreous conditions. IOP, intraocular pressure.

with scleral indentation in the present study. In the previous report, they concluded that there was no statistically significant difference in IOP fluctuations between $23 \mathrm{G}$ and $25 \mathrm{G}$ vitrectomy [7]. On the other hand, in another study, it was concluded that $23 \mathrm{G}$ probes lead to a lower IOP drop and smaller pressure overshooting than did 25G probes [21]. When using the Constellation system, the diameter of the cutter is smaller in the case of $27 \mathrm{G}$ vitrectomy, but the suction efficiency and the duty cycle are also lower. We hypothesize that the change in IOP was more stable due to the prevention of a rapid increase in the flow rate. The EVA system has a mechanism to adjust the pressure in response to the suction pressure, termed the "diafragma method" and "AIC." Similar to that in the Constellation system, $27 \mathrm{G}$ vitrectomy lowers the suction efficiency in the EVA system, but IOP is more stable.

The EVA vacuum mode keeps the vacuum pressure constant, and the EVA flow mode keeps the flow volume constant. In this study, the $27 \mathrm{G} \mathrm{EVA}$ flow mode produced optimal IOP stability when compared with the other conditions we investigated. In particular, IOP is most stable during fluid-gas exchange. A possible explanation is that, during the final stage of fluid-gas exchange, it is highly likely that, when aspirating the last drop of BSS, air will be aspirated. In a vacuum-based system, this can cause a large drop in IOP due to the difference in viscosity of BSS and air. By applying the EVA flow mode, a smooth fluidgas transition is guaranteed, as the aspirated flow remains constant for both BSS and air. 
It should be noted that the current study had some limitations. We used porcine eyes, as its scleral rigidity has been reported to be similar to that of the human eye [22]. However, experiments performed in porcine eyes are ex vivo, and the vitreous cavity in the human eye is smaller than that in the porcine eye; therefore, the results cannot be directly related to the human eye.

In conclusion, we confirmed that, regardless of the aspiration system, IOP fluctuation was lower during $27 \mathrm{G}$ vitrectomy than during $25 \mathrm{G}$ vitrectomy. In addition, the $27 \mathrm{G}$ EVA flow mode, with brief flow rate control, produced optimal IOP stability when compared with the other conditions in the present study.

\section{Statement of Ethics}

This study was approved by the Committee for Safe Handling of Living Modified Organisms at the Kyoto Prefectural University of Medicine (Permission No. B2020-14) and carried out according to the guidelines of the committee.

\section{Conflict of Interest Statement}

The authors have no conflicts of interest to declare. The authors have no proprietary or commercial interest in any of the products described in this article.

\section{Funding Sources}

The entire study was performed and completed at the Department of Ophthalmology, Kyoto Prefectural University of Medicine, Kyoto, Japan, without any support from grants or other funding.

\section{Author Contributions}

Y.S. and K.Y. designed and performed the experiments. Y.S. analyzed the data. Y.S., K.Y., and C.S. generated the figures and tables, drafted and revised the manuscript, and approved the final manuscript.

\section{References}

1 Findl O, Strenn K, Wolzt M, Menapace R, Vass C, Eichler HG, et al. Effects of changes in intraocular pressure on human ocular haemodynamics. Curr Eye Res. 1997 Oct;16(10): 1024-9.

2 Brubaker RF. Intraocular surgery and choroidal hemorrhage. Arch Ophthalmol. 1984 Dec: 102(12):1753-4.

3 Parrish R, Gass JD, Anderson DR. Outer retina ischemic infarction: a newly recognized complication of cataract extraction and closed vitrectomy. Part 2. An animal model. Ophthalmology. 1982 Dec;89(12):1472-7.

4 Tabandeh H, Sullivan PM, Smahliuk P, Flynn HW Jr, Schiffman J. Suprachoroidal hemorrhage during pars plana vitrectomy. Risk factors and outcomes. Ophthalmology. 1999 Feb;106(2):236-42.

5 Speaker MG, Guerriero PN, Met JA, Coad CT, Berger A, Marmor M. A case-control study of risk factors for intraoperative suprachoroidal expulsive hemorrhage. Ophthalmology. 1991 Feb;98(2):202-10; discussion 210.

6 Moorhead LC, Gardner TW, Lambert HM, O’Malley RE, Willis AW, Meharg LS, et al. Dynamic intraocular pressure measurements during vitrectomy. Arch Ophthalmol. 2005 Nov;123(11):1514-23.

7 Sugiura Y, Okamoto F, Okamoto Y, Hiraoka $\mathrm{T}$, Oshika T. Intraocular pressure fluctuation during microincision vitrectomy with constellation vision system. Am J Ophthalmol. 2013 Nov;156(5):941-e1.
8 Michelson G, Groh MJ, Langhans M. Perfusion of the juxtapapillary retina and optic nerve head in acute ocular hypertension. Ger J Ophthalmol. 1996 Nov;5(6):315-21.

9 Minami M, Oku H, Okuno T, Fukuhara M, Ikeda T. High infusion pressure in conjunction with vitreous surgery alters the morphology and function of the retina of rabbits. Acta Ophthalmol Scand. 2007 Sep;85(6):633-9.

10 Moorhead LC, Armeniades CD. Variations in intraocular pressure during closed-system surgical procedures. Arch Ophthalmol. 1986 Feb;104(2):269-72.

11 Kim SH, Choi KS. Changes of intraocular pressure during experimental vitrectomy. Curr Eye Res. 2012 Aug;37(8):698-703.

12 Okamoto F, Sugiura Y, Okamoto Y, Hasegawa Y, Hiraoka T, Oshika T. Measurement of ophthalmodynamometric pressure with the vented-gas forced-infusion system during pars plana vitrectomy. Invest Ophthalmol Vis Sci. 2010 Aug;51(8):4195-9.

13 Yang HS, Yun YI, Park JH, Choi S, Woo JM. In vivo intraocular pressure monitoring during microincision vitrectomy with and without active control of infusion pressure. Eur J Ophthalmol. 2017 Aug 30;27(5):601-6.

14 Oshima Y, Wakabayashi T, Sato T, Ohji M, Tano Y. A 27-gauge instrument system for transconjunctival sutureless microincision vitrectomy surgery. Ophthalmology. 2010 Jan;117(1):93-e2

15 Mitsui K, Kogo J, Takeda H, Shiono A, Sasaki $\mathrm{H}$, Munemasa Y, et al. Comparative study of 27 -gauge vs. 25 -gauge vitrectomy for epiretinal membrane. Eye. 2016 Apr;30(4):538-44.
16 Rizzo S, Barca F, Caporossi T, Mariotti C. Twenty-seven-gauge vitrectomy for various vitreoretinal diseases. Retina. 2015 Jun;35(6): 1273-8.

17 Khan MA, Shahlaee A, Toussaint B, Hsu J, Sivalingam A, Dugel PU, et al. Outcomes of 27 gauge microincision vitrectomy surgery for posterior segment disease. Am J Ophthalmol. 2016 Jan;161:36-43.e12.

18 Yoneda K, Morikawa K, Oshima Y, Kinoshita S, Sotozono C; Japan Microincision Vitrectomy Surgery Study Group. Surgical outcomes of 27-gauge vitrectomy for a consecutive series of 163 eyes with various vitreous diseases. Retina. 2017 Nov;37(11):2130-7.

19 Shinkai Y, Oshima Y, Yoneda K, Kogo J, Imai $\mathrm{H}$, Watanabe A, et al. Multicenter survey of sutureless 27-gauge vitrectomy for primary rhegmatogenous retinal detachment: a consecutive series of 410 cases. Graefes Arch Clin Exp Ophthalmol. 2019 Dec;257(12):2591-600.

20 Kim YJ, Park SH, Choi KS. Fluctuation of infusion pressure during microincision vitrectomy using the constellation vision system. Retina. 2015 Dec;35(12):2529-36.

21 Falabella P, Stefanini FR, Lue JC, Pfister M, Reyes-Mckinley J, Koss MJ, et al. Intraocular pressure changes during vitrectomy using constellation vision system's intraocular pressure control feature. Retina. 2016 Jul;36(7): 1275-80.

22 Pierscionek BK, Asejczyk-Widlicka M, Schachar RA. The effect of changing intraocular pressure on the corneal and scleral curvatures in the fresh porcine eye. Br J Ophthalmol. 2007 Jun;91(6):801-3. 